\title{
ARTIGO
}

\section{Indicadores estratégicos em ciência e tecnologia: refletindo a sua prática como dispositivo de inclusão/exclusão}

\author{
Science and technology strategic \\ indicators: reflecting their practice \\ as a means of inclusion/exclusion
}

Raimundo Nonato Macedo dos SANTOS ${ }^{1}$

\section{RE S U M O}

\begin{abstract}
A ciência, enquanto atividade, é uma construção social complexa que requer ousadia e altos investimentos. Não é neutra, nem extemporânea; grassa na concentração do seu labor, o que, em conseqüência, favorece o monopólio econômico dos seus resultados. Elitiza-se, materializa-se no efeito São Mateus: a quem tem, mais Ihe será dado. Portanto, boas intenções e contradições requerem reflexões, questionamentos, discussões, crítica e massa crítica. Tal é a área de concentração da "Ciência das Ciências", contemplada neste trabalho.
\end{abstract}

Palavras-chave: produção científica, bibliometria, cientometria, ciência das ciências.

\section{A B S T R A C T}

Science, as an activity, is a complex social construction, requiring boldness and high investments. It is neither neutral, nor extemporaneous; it expands itself in the concentration of labor put on it; consequently, it favors the economical

\footnotetext{
${ }^{1}$ Doutor em Ciência da Informação e da Comunicação pela Université Aix-M arseille III, F rança. Professor Titular, Curso de Pós-Graduação em Ciência da Informação, Pontifícia Universidade Católica de Campinas. Praça da Imaculada, 105, Vila Santa Odila, 13045-901, Campinas, SP, Brasil. E-mail: rnsantos@puc-campinas.edu.br
} 
monopoly of its results. It becomes elitist and materializes itself in what may be called the Saint Mathews effect: To those who have, more will be given. Good intentions and contradictions require reflection, questioning, discussion, criticism and critical mass. Such is the area of concentration of the "Sciences' science", the subject of this paper.

Key words: scientific production, the science of sciences, bibliometric, scientometric.

\section{N T R O D U Ç Ã O}

Nos últimos anos tem sido crescente o interesse de especialistas e autoridades governamentais por indicadores quantitativos que, além de auxiliarem no entendimento da dinâmica de ciência e tecnologia (C\&T), funcionam também como instrumentos para o planejamento de políticas e tomada de decisões neste setor.

Depois da Segunda Guerra, os países cientificamente avançados, deixaram a cargo de cientistas o poder de decisão no segmento de C\&T, confiando em sua visão e competência, comprovadas por sucessos em áreas estratégicas, principalmente na de energia nuclear. Contudo, o surgimento de novos desafios sócio-econômicos, - derivados, em grande parte, do enorme avanço científico-tecnológico das últimas décadas -, tornou tal modelo ineficaz.

Sua reestruturação exigiu a incorporação de políticos e burocratas que, por sua vez, passaram a demandar indicadores quantitativos que mostrassem claramente as tendências do setor de C\&T e as conseqüências das políticas implantadas. Nesse cenário, o papel dos pesquisadores voltou a destacar-se, não só pela sua capacidade de equacionar problemas científicos e desenvolver soluções como de propor e validar tais indicadores, definindo seus alcances e limitações.

Surgiu então uma nova área, a "cienciometria" ou "cientometria", cuja meta é gerar informações e discussões que contribuam para a compreensão e a própria superação dos desafios característicos da ciência moderna.
A cientometria, tal qual se apresenta hoje, constitui-se fundamentalmente um reducionismo bibliométrico. Por sua vez, as premissas conceituais da bibliometria remontam ao início do século XIX. Desde então, os fundamentos, as técnicas, as aplicações dos métodos bibliométricos evoluíram sobremaneira graças a inúmeras pesquisas.

Esta abundância de trabalhos e, sobretudo a variedade de objetivos buscados tornaram confusa a idéia do que se pode fazer com a bibliometria, a tal ponto que, mesmo entre os especialistas da área há dificuldade de chegarem a um acordo a respeito de noções cruciais como: a terminologia empregada (bibliometria, cientometria, informetria, tecnometria); definições dos limites de aplicação (biblioteconometria, avaliação da pesquisa, sociologia da ciência, avaliação macro-econômica, sociologia da inovação, inteligência competitiva, tratamento de linguagem natural) e, mais importante de tudo, sobre a evolução e o futuro profissional dos seus especialistas (ROSTAING, 1996).

Com base nessa premissa, este trabalho tem como objetivo apresentar uma compilação da literatura científica, tratando dos sistemas de informação e da própria evolução do arcabouço teórico e metodológico da área.

\section{Aspectos contextuais, terminológicos e metodológicos}

Para avaliar as potencialidades da base científica e tecnológica dos países, monitorar as oportunidades em diferentes áreas e identificar 
atividades e projetos mais promissores para o futuro, auxiliando as decisões estratégicas dos gestores da política científica e tecnológica, tornan-se necessários a formulação, o desenvolvimento e a implementação de sistemas de informações científica e técnica, para produzir indicadores, métodos e ferramentas afins.

\section{O S SISTEM AS DE IN FORM AÇÃ O CIENTÍFICA E TÉ CNICA PARA A PRODUÇÃ O DE IN DICA DORES CIEN TÍFICOS}

No processo de análise das informações científicas e técnicas para a produção de indicadores, encontrar a fonte de dados primários, em suporte magnético, mais adequada às necessidades de produção dos indicadores é a parte mais difícil. Em geral, as fontes de dados primários, em suporte magnético, não foram construídas para a produção dos indicadores, havendo necessidade de reformatarem- $\mathrm{se}^{2}$ os campos antes da importação dos dados, operação sempre complicada (QUONIAM, 1992).

Porém, o crítico do contexto dos dados primários é que existem somente duas bases de dados, com cobertura global e completas dos seus assuntos, reconhecidamente estruturadas para análise de informação para a produção de indicadores, sem necessidade de grandes manipulações prévias nos dados: a Web of Science e a World Patent Index. A primeira especializada em informação científica e a segunda em informação técnica, no domínio das patentes ${ }^{3}$.

Limitadas a essas condições, as informações relatadas a seguir refletem o que se pode dispor em termos de dados para a elaboração de estudos, tendo em vista, a produção de indicadores científicos em escala global. Por outro lado, para medir a produtividade científica nacional, bem como, para elaborar estudos sobre as relações que se estabelecem entre os pesquisadores, várias iniciativas de implantação de sistemas de informação em nível institucional, mas também, de entidades não- governamentais, são destacadas.

\section{0 acervo científico do ISI}

Estima-se que circulem hoje, pelo mundo, cerca de um milhão de periódicos científicos. Menos de um por cento desse volume, aproximadamente 8.500, encontra-se indexado nos bancos de dados do Institute for Scientific Information (ISI), situado na Filadélfia, EUA. Os periódicos são indexados nessa base após rigorosa seleção, o que qualifica essa fonte de dados como uma das mais conceituadas do mundo (SANTOS et al., 2002).

São três as bases de dados existentes no ISI. A primeira e mais antiga (1961) é a Science Citation Index (SCI) multidisciplinar, que indexa mais de 5.700 dos principais periódicos referentes a 164 áreas do conhecimento (hard sciences). A base SCl online, cobrindo aproximadamente 2.100 periódicos a mais que suas versões impressa e em CD-ROM, permite acesso às referências citadas nas publicações. A velocidade de atualização é impressionante: 17.750 novos artigos são incorporados por semana. A versão online contém mecanismos de busca para cerca de $70 \%$ desse total, disponibilizando integralmente os abstracts dos artigos. Exemplos de disciplinas incluídas na base: agricultura, neurociência, astronomia, bioquímica, biologia, biotecnologia, física, química, ciência da computação e matemática.

\footnotetext{
2 Reformatar: ação tendo em vista dispor uma informação segunda uma estrutura - formato de entrada - para o tratamento dentro de um sistema documentário (CHAUMIER, 1986).

${ }^{3}$ DIALOG BLUESHEETS from Dialog Coorporation. Available from: «ttp://library.dialog.com/bluesheets/>. Acess: 15 jun. 2001.
} 
No campo das ciências sociais, o ISI oferece uma base semelhante, a Social Sciences Citation Index (SSCI), lançada em 1972. Ela indexa mais de 1.725 periódicos, que abrangem 50 áreas do conhecimento. Inclui, em média, 2.700 novos artigos por semana. Contém mecanismos de busca que disponibilizam abstracts para $60 \%$ desses trabalhos. Entre as disciplinas cobertas pela base figuram história, direito, sociologia, lingüística, psicologia, antropologia, ciência política, saúde pública e estudos urbanos.

A terceira base indexada no ISI é a Arts \& Humanities Citation Index (AHCl), surgida em 1978. Ela indexa 1.144 periódicos da área de artes e humanidades e introduz semanalmente 2.250 novos artigos, em média.

A representatividade da base $\mathrm{SCI}$ para a produção internacional, especialmente em certos domínios (como Física e Biologia, por exemplo), é pouco contestada pela comunidade científica, por ser das mais completas e aprofundadas. $\mathrm{O}$ mesmo não ocorre com a base SSCl, composta por disciplinas sociais que, por sua natureza, são menos internacionalizadas. Muitas das mais conceituadas e "nobres" publicações da área (como as européias), cujos periódicos não têm o inglês como língua mãe, não são por ela indexadas. Isso faz com que o meio acadêmico encare a Social Sciences Citation Index com certa reserva, considerando baixa sua representatividade e recomendando sua utilização com cautela.

Mesmo em relação às hard sciences, argumenta-se que há certo viés do $\mathrm{SCl}$ em benefício dos periódicos e publicações em língua inglesa, e especificamente dos norte-americanos, que predominam amplamente na base, ficando a ciência européia, em geral, e a dos países em desenvolvimento, em particular, sub-representadas. Em algumas áreas científicas, especialmente aquelas que têm um caráter mais aplicado, como a agricultura e as profissões da saúde, essa distorção se vê acentuada.

\section{SciELO, uma base brasileira}

A Scientific Electronic Library Online (SciELO) é uma biblioteca virtual que disponibiliza periódicos científicos brasileiros relacionados a sete áreas: Ciências Agrícolas, Ciências Biológicas, Química, Engenharia, Geociências, Ciências da Saúde e Ciências Humanas.

Desenvolvida a partir de um projeto executado em parceria pela Fundação de Amparo à Pesquisa do Estado de São Paulo (FAPESP) e pelo Centro Latino-Americano e do Caribe de Informação em Ciências da Saúde (BIREME), o endereço <www.scielo.br/scielo > encontra-se em formação. Deverá ser ampliado para atender a uma política que visa aumentar radicalmente, no curto prazo, a visibilidade e a credibilidade nacional e internacional das publicações científicas da América Latina e do Caribe. A proposta é oferecer amplo acesso a coleções de periódicos como um todo, aos fascículos de cada título de periódico e aos textos completos dos artigos.

Em termos cronológicos, a coleção de cada título individual começa em 1997, para revistas em circulação, ou a partir do primeiro número, para revistas criadas após 1997. As contribuições podem ser escritas em inglês, português e espanhol. Quanto ao suporte material, os periódicos da coleção não deverão, necessariamente, ser publicados na forma impressa.

\section{Plataforma Lattes: Bases de dados de Currículos e de Diretório de Grupos de Pesquisa em C\&T no Brasil}

A Plataforma Lattes é um conjunto de sistemas de informações, bases de dados e portais Web, voltado para a gestão de Ciência e Tecnologia. Foi concebida para integrar os sistemas de informações das agências federais, racionalizando o processo de gestão de C\&T.

A base de dados de currículos constitui-se de um formulário eletrônico do Ministério 
de Ciência e Tecnologia (MCT), do Conselho Nacional de Desenvolvimento Científico e Tecnológico (CNPq), da Finep e da Coordenação de Aperfeiçoamento de Pessoal de Nível Superior (CAPES) / Ministério da Educação (MEC) para o cadastro de dados curriculares de pesquisadores e de usuários em geral. Seus dados são utilizados para:

- avaliação da competência de candidatos à obtenção de bolsas e auxílios;

- seleção de consultores, de membros de comitês e de grupos assessores;

- subsídio à avaliação da pesquisa e da pós-graduação brasileiras.

A base de dados de Diretório dos Grupos de Pesquisa no Brasil foi desenvolvida pelo CNPq desde 1992. Ela contém informações sobre os grupos de pesquisa em atividade no País.

As informações constantes na base dizem respeito aos recursos humanos constituintes dos grupos, às linhas de pesquisa em andamento, às especialidades do conhecimento, aos setores de aplicação envolvidos, aos cursos de mestrado e doutorado com os quais o grupo interage, à produção científica e tecnológica e aos padrões de interação com o setor produtivo. Cada grupo constante na base está situado no espaço e no tempo.

Os grupos de pesquisa inventariados estão localizados em universidades, instituições isoladas de ensino superior, institutos de pesquisa científica, institutos tecnológicos, laboratórios de pesquisa e desenvolvimento de empresas estatais ou ex-estatais e em algumas organizações não-governamentais, com atuação em pesquisa científica ou tecnológica.

A base de dados de Diretório dos Grupos de Pesquisa no Brasil tem três finalidades principais:

- Para a comunidade científica e tecnológica, no dia-a-dia do exercício profissional, constitui-se em um instrumento para o intercâmbio e a troca de informações. Provê respostas sobre: quem é quem, onde se encontra, o que está fazendo e o que produziu recentemente.

- Para o planejamento e a gestão das atividades de C\&T, disponibiliza informações sobre a constituição dos grupos de pesquisa, sua distribuição espacial, relações estabelecidas, domínios cobertos pelos grupos, série históricas sobre a formação dos grupos e demais dados estatísticos, apresentados em formas de tabela ou de gráficos.

- Finalmente, na medida em que se pretende recorrente, tem o importante papel na preservação da memória da atividade científicotecnológica no Brasil.

Para que esses objetivos possam ser alcançados de forma plena, o CNPq determinou que, a partir de 2002, todos os bolsistas de pesquisa, de mestrado, doutorado e de iniciação científica, orientadores credenciados e outros clientes do Conselho, bem como, pesquisadores e estudantes participantes de diretórios de grupo de pesquisa no Brasil cadastrassem seus currículos Lattes no CNPq. A inexistência do currículo impedirá pagamentos e renovações de bolsas.

Em agosto de 2003, a Plataforma Lattes contava com 305.376 registros de currículos Lattes e, segundo senso de 2002, de 115.158 grupos de pesquisa, distribuídos conforme a Tabela 1.

Tabela 1. Distribuição dos grupos de pesquisa segundo a região geográfica, 2002.

\begin{tabular}{lcr}
\hline Região & Grupos & $\%$ \\
\hline Sudeste & 7.855 & 51,8 \\
Sul & 3.630 & 24,0 \\
Nordeste & 2.274 & 15,0 \\
Centro-oeste & 809 & 5,3 \\
Norte & 590 & 3,9 \\
Brasil & 15.158 & 100,0 \\
\hline
\end{tabular}




\section{A SPECTOS TERM INOLÓ G ICOS E METODOLÓGICOS USADOS NO PROCESSO DE PRO D U ÇÃ O DE IN DICADORES}

Para não se perder o essencial da informação, e para se assegurar da cobertura, a mais completa possível, do assunto analisado, faz-se uso, no processo de produção dos indicadores, de uma massa considerável de dados e/ou de informação (QUONIAM, 1992).

Face a essa situação, a questão que se impõe é para encontrar métodos e técnicas que permitam extrair sentido nessa massa de informação, sem, no entanto, ter que ler documento por documento, o que tornaria inviável o processo (ROUSEAU-HANS \& THIL, 1997).

\section{A cientometria e suas relações com a bibliometria}

Os termos "cientometria" e estudos quantitativos da ciência e da tecnologia poderiam ser considerados sinônimos. No entanto, para o mesmo significado, o termo "bibliometria" é também consagrado pela sua considerável interface nos estudos quantitativos ou cientométricos. Há ainda, o termo "tecnometria", por vezes utilizado para designar os estudos quantitativos da tecnologia (XAVIER, 1995).

Em 1962, a partir dos estudos estatísticos aplicados à mão-de-obra e à literatura científica, Price observou que essas práticas obedeciam a leis gerais, e que os métodos empíricos aplicados para apurar periódicos e artigos, na determinação dos indicadores científicos, produziam coerência teórica, com representações de curvas estáveis e regulares (PRICE, 1963).

Em 1969, Pritchard definia a bibliometria como: "a aplicação de métodos matemáticos e estatísticos a livros, artigos e outras mídias de comunicação" (PRICTCHARD, 1969).

Neste mesmo ano, Price definiu a cientometria como: "as pesquisas quantitativas de todas as coisas que dizem respeito à ciência e, aos quais podem ser atribuídos números (grifos do autor)" (PRICE, 1969). Esta definição tão ampla da cientometria, interpretada segundo o material publicado na revista Scientometrics ${ }^{4}$, ou seja, "estudos de avaliação de publicações (periódicos, artigos, patentes) de autores, de citação", evidencia que, do ponto de vista da prática, a cientometria restringe-se a aplicações bibliométricas (BROADUS, 1987).

Tal constatação é reforçada pelo fato de que existem bases de dados bibliográficas que cobrem com precisão e exclusividade a informação tipo científica e técnica (publicações científicas e de patentes). Neste sentido, a hipótese que se sustenta é que: "publicações científicas e de patentes constituem-se fontes de informações e assumem papel destacado e inconteste como indicadores de produção de conhecimentos certificados no domínio das ciências e das técnicas" (XAVIER, 1995).

Da mesma forma, aceitando-se os dois postulados abaixo enunciados, implícitos em todos os métodos de análise bibliométrica, explicita-se que: os estudos das publicações científicas permitem vincular os conhecimentos e suas estruturas segundo as escolas de pensamento e suas evoluções" e que, portanto, do ponto de vista da prática, reforça-se a idéia, já anteriormente explicitada de que, em síntese, a cientometria é um reducionismo bibliométrico (PRICE, 1963).

Primeiro postulado: uma obra científica é o produto objetivo da atividade intelectual criativa. Num contexto científico, uma publicação é uma representação da atividade de pesquisa de seu autor. O maior esforço deste autor é de persuadir os pares de que suas descobertas, seus métodos

4 Scientometrics, revista fundada em 1978, voltada para publicação de estudos, pesquisa no âmbito da produção científifica. 
e técnicas são particularmente pertinentes. 0 modo de comunicação escrita fornecerá, portanto, todos os elementos técnicos, conceituais, sociais e econômicos que o autor busca afirmar ao longo de sua argumentação.

Segundo postulado: a atividade de publicação científica é uma eterna confrontação entre as reflexões intrínsecas do autor e os conhecimentos que ele adquiriu pela leitura dos trabalhos originários dos outros autores. Desta forma, a publicação é o resultado de uma comunicação entre a razão individual e a coletiva. Assim, os pesquisadores, para consolidar suas argumentações, fazem referência aos trabalhos dos outros pesquisadores que constituem, com esse arranjo, um certo consenso na comunidade científica. Deste fenômeno, pode-se dizer que: existe uma relação entre todos os trabalhos científicos publicados, não sendo possível, no entanto, precisar o tipo de relação: se direta ou indireta, reconhecida ou dissimulada, consciente ou inconsciente, acordada ou não.

Esses postulados, que foram inicialmente definidos para fins da pesquisa científica, foram, em seguida, admitidos como válidos para as publicações reunindo conhecimentos técnicos ou tecnológicos: as patentes. Apoiando-se sobre esses dois postulados, o princípio da bibliometria é de analisar a atividade científica ou técnica através de estudos quantitativos das publicações (grifos meus). Os dados quantitativos são calculados a partir de contagens estatísticas das publicações ou de elementos extraídos das mesmas. Desta forma, pode-se dizer que, a bibliometria é um termo genérico, que reúne uma série de técnicas estatísticas buscando quantificar os processos da comunicação escrita (ROSTAING, 1996).

Ao introduzir o termo bibliometria, Pritchard pretendeu substituir a expressão "bibliografia estatística" que vinha sendo empregada desde 1923, data em que (HULME, 1923) apresentou o seu trabalho. Pritchard argumentava que "bibliografia estatística" poderia dar margem a interpretações distorcidas como, por exemplo, dar a entender tratar-se de uma bibliografia a respeito de estatística (PRITCHARD, 1969).

Devido ao fato de que a definição proposta por Pritchard não dava nenhuma indicação da finalidade da bibliometria e, das aplicações bibliométricas haverem sido, por longo tempo, fortemente atreladas ao domínio da gestão de bibliotecas e de centros de documentação, certamente pela ênfase econométrica que sugeria, estudos bibliométricos sobre circulação das publicações, que ultrapassavam fronteiras eminentemente biblioteconométricas, não chegavam a ser destacados com a mesma importância destes.

Foi, para distinguir estes dois tipos de aplicação, que apareceu o termo "cientometria". Numa conferência, Brookes estabeleceu esta distinção.

Então que a bibliometria teria por objeto estudar os livros ou as revistas científicas e por objetivo compreender as atividades de comunicação da informação, a cientometria teria por objeto estudar aspectos quantitativos da criação, difusão e utilização da informação científica e técnica e por objetivo a compreensão dos mecanismos de pesquisa como atividade social (grifos do autor) (BROOKES, 1987).

Assim, a bibliometria reagruparia o conjunto dos métodos para ajudar a gestão da biblioteca e a cientometria pesquisaria as leis que regem a ciência, daí sua denominação "Ciência da Ciência" por Solla Price (ROSTAING, 1996).

Faz-se necessário observar-se ainda que, os estudos quantitativos da ciência e da tecnologia comportam uma abordagem de pesquisa aplicada e uma outra de pesquisa fundamental. A primeira obedece preponderan- 
temente à demanda por indicadores quantitativos de ciência e da tecnologia da parte dos gestores de política científica, pública ou privada. Quanto ao segundo, considera-se que os métodos quantitativos e, principalmente, a análise de dados constituem um elemento indispensável para fazer avançar a nossa compreensão sobre os estudos da ciência como um sistema complexo de produção e de troca de conhecimentos (VAN RAAN, 1988).

\section{O S IN D ICA D ORES: \\ ESPECIFICIDADES E C O N S TR U Ç Ã O}

$\mathrm{Na}$ atividade de pesquisa, as medidas e os números são utilizados para analisar os dados a fim de aperfeiçoar a qualidade dos seus estudos (RAVICHANDRARAO, 1986). No termo cientometria, o sufixo "metria" dá margem tanto ao sentido de métrica como de medida. Em relatório encomendado para a Secrétariat General de la Défense Nationale (SGDN) - France, Dutheiul faz distinção entre esses dois sentidos:

A métrica aplica-se a um conjunto para o qual aceita-se uma convenção, permitindo definir as 'distâncias' entre os elementos, o que se constitui em classificar por semelhança ou dessemelhança. A medida é a avaliação de uma grandeza criada a partir de sua relação com uma outra grandeza de mesma espécie adotada para unidade e como comparação (DUTHEIUL, 1991).

Consubstanciando os dois postulados já mencionados, os métodos cientométricos situam-se entre os sentidos da medida e da métrica:

- O conceito de medida está bem representado pelos estudos cientométricos utilizando indicadores univariáveis ${ }^{5}$, em que cada elemento em estudo é medido segundo uma dimensão escolhida (ROSTAING, 1996).

- Por outro lado, o conceito de métrica é mais apropriado para indicadores relacionais. Neste caso, as comparações entre os elementos bibliográficos não são estabelecidos a partir de referenciais a uma só dimensão, mas a partir de fatores influentes. Os métodos empregados buscam representar os elementos segundo cálculos de "distância" que deverão estimar graus de "semelhança" ou de "dessemelhança" entre os elementos. Exemplo marcante, neste sentido, é o caso do método de análise de co-citação ${ }^{6}$ (CALLON et al., 1993).

A cientometria é portanto um dispositivo de medida, baseado em técnicas estatísticas, que tem por objetivo identificar e tratar as informações contidas nas publicações científicas e técnicas, disponíveis nos sistemas de informação, essencialmente, referências bibliográficas de artigos, de livros e de patentes; razão pela qual torna-se importante analisar o papel destas diferentes publicações nas atividades dos pesquisadores.

Para uma explicitação mais do ponto de vista pedagógico, sobre a análise do papel destas publicações para os fins propostos neste trabalho - indicadores estratégicos em ciência e tecnologia -, optou-se pela utilização de uma abordagem do Centre de Sociologie de Innovation $^{7}$, fundada no princípio de que a pesquisa é uma atividade cuja natureza e resultados podem ser analisados e avaliados

\footnotetext{
${ }^{5}$ Indicadores univariáveis: medida puramente quantitativa, baseada na simples contagem ou no cálculo de coeficientes entre diferentes elementos bibliográficos.

${ }^{6}$ Aparição simultânea de duas citações, formando um par que se repete em um grande número de publicações.

70 "Centre de sociologie e innovation" é um laboratório da "École dês Mines de Paris". Seus trabalhos são consagrados à Sociologia das Ciências e das Técnicas, bem como, à Sócio-economia da Inovação. É um dos raros centros de pesquisa da França tendo desenvolvido métodos científicos originais.
} 
segundo 5 dimensões principais, constituindo o que eles vieram a denominar de "a rosa dos ventos" da pesquisa, (Figura 1) (CALLON et al., 1993)

1) a pesquisa contribui para a produção de conhecimentos cuja qualidade e interesse são avaliados pela comunidade científica, razão pela qual, diz-se que estes conhecimentos são "certificados".

A comunidade científica coloca os pesquisadores em estado de concorrência. A competição estimula a produção de conhecimentos. Como conseqüência da competição, os conhecimentos gerados precisam ser atestados: somente sobrevivem e se expandem os resultados que resistem à crítica coletiva: "índice de citação e co-citação". Esta pesquisa é geralmente qualificada de "acadêmica".

2) a pesquisa pode dar origem a um processo de valorização econômica, que conduz à geração de inovações, ou seja, à comercialização de novos produtos e procedimentos.

As inovações inscrevem-se nas estratégias das empresas para criar o que os economistas nomeiam de "vantagens competitivas", indicador que fixa a superioridade de uma organização face aos concorrentes. Neste caso, a pesquisa obedece à lógica da competição econômica e a avaliação repousa sobre a contribuição que a pesquisa proporciona à atividade industrial.

3) a pesquisa pode ser igualmente mobilizada para contribuir para ações de "interesse geral".

Algumas pesquisas de interesse público tomam a forma de programa, tendo como objetivo realizar objetos técnicos complexos como, por exemplo, um avião de combate, um satélite meteorológico ou um programa nuclear para fins de geração de energia. Em outros casos, a finalidade dos programas é mais difusa: pesqui-

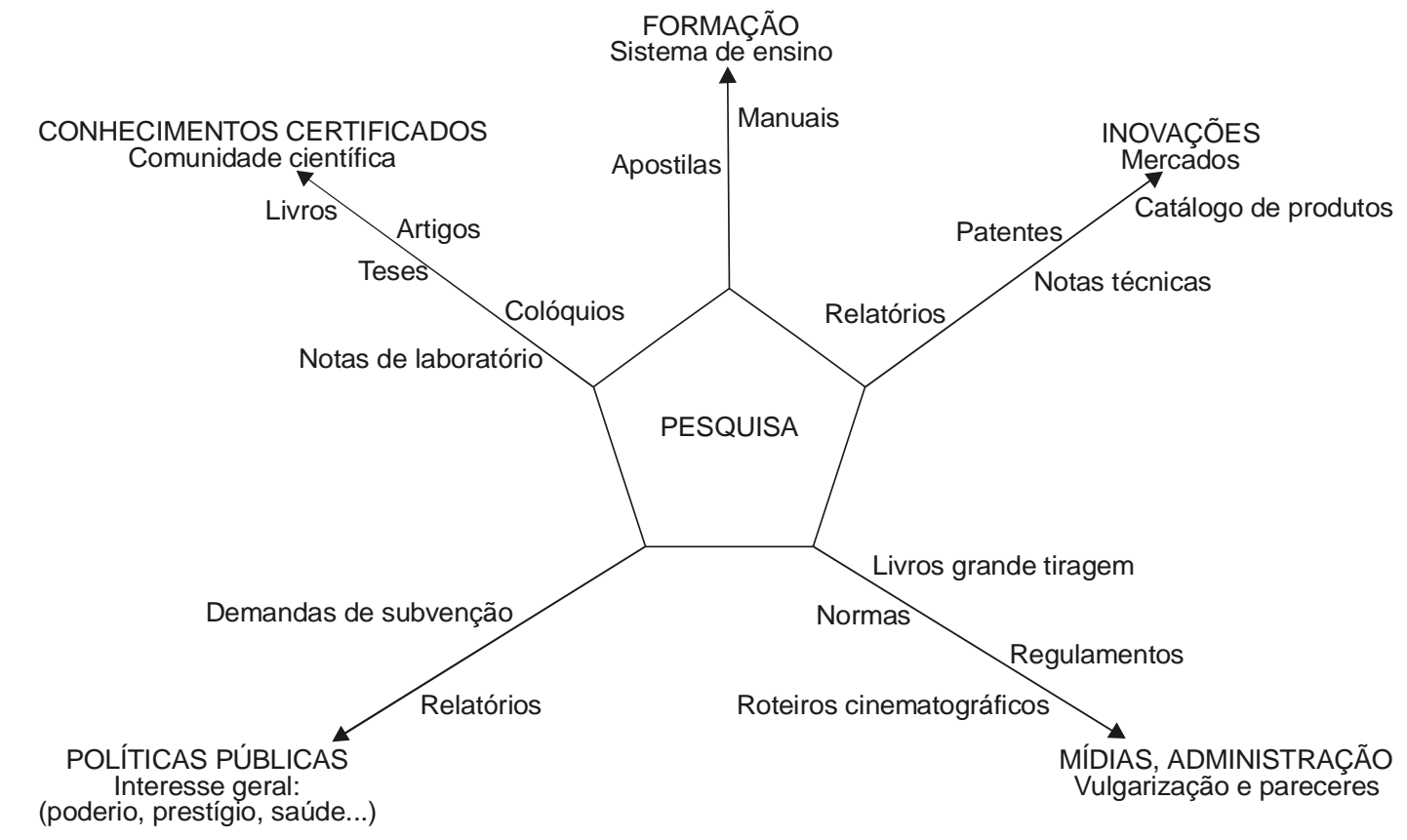

Fonte: Centre de sociologie e innovation.

Figura 1. A rosa dos ventos da pesquisa. 
sadores e tecnólogos estabelecem investigações epidemiológicas; inspecionam a camada de ozônio em busca de buracos; realizam investigações sobre espécies animais ameaçadas de extinção.

No caso de programa voltado para objetivos de interesse geral, a pesquisa é colocada sobre a tutela de uma agência ou de organismos públicos. Neste caso, o mecanismo de regulação não é, nem indicadores de acumulação de conhecimentos em si, nem a geração de uma vantagem competitiva e sim algo de mais qualitativo (poderio, prestígio, bem-estar social) materializado através do julgamento político e do debate público que suscita.

4) a contribuição às atividades de formação constitui para a pesquisa um espaço de aplicação essencial.

Os conhecimentos e as práticas elaborados pelos pesquisadores são, dessa maneira, transformados em competências incorporadas nos indivíduos (estudantes, participantes de cursos profissionalizantes) que, na seqüência os colocam em prática nos diferentes setores de atividade: indústria, serviços públicos, ensino, pesquisa. A sistematização dos conhecimentos, a sua organização, com vistas a sua transmissão, obedecem a lógicas estreitamente dependentes da maneira como as instituições de formação praticam a concorrência entre elas e das suas relações de práticas comerciais com o mercado.

5) a pesquisa não pode se desenvolver junto a uma sociedade hostil à ciência e ao progresso técnico.

Pesquisadores e tecnólogos sempre se esforçaram para apresentar suas atividades de forma a despertar interesse para um público dito não iniciado, seja satisfazendo sua curiosidade, seja fazendo-o interessar-se por certos resultados esperados ou desejados.

A forma utilizada para esta ação é múltipla: publicações de obras ou de realizações de emissões de vulgarização; campanhas de mobilização da opinião para apoiar pesquisas sobre problemas maiores - proteção ao meio ambiente, combate à dengue, combate à fome: Ação da Cidadania Contra Fome e a Miséria e pela Vida, do Betinho.

Quando cientistas, pesquisadores engajam-se em debates sobre o reaquecimento da atmosfera, ou sobre o desaparecimento da camada de ozônio, estão, de uma forma ou de outra, plasmando os conhecimentos que eles produziram, num espaço público, num fórum de debate com outros setores. Da mesma forma, quando eles contribuem para a elaboração de normas de segurança para centrais nucleares ou, na redação para a proteção do meio ambiente ou, na negociação de cotas de pescas em zonas costeiras, eles intervêm na condição de especialistas para fazer valer o ponto de vista da ciência ou da técnica.

Nestas situações, o pesquisador é um especialista entre outros, e seu ponto de vista, em geral, determinante, não será o único a ser considerado. Em síntese, isto quer dizer que: quando autoridades participam de iniciativas de vulgarização e de emissão de pareceres, os pesquisadores submetem-se a formas específicas de avaliação e de gratificação: o impacto de uma obra de vulgarização mede-se em número de exemplares vendidos; o sucesso de uma campanha de pesquisa contra o câncer, por exemplo, é função do volume de fundos arrecadados; um parecer emitido por um pesquisador, traduz-se por opiniões ou recomendações que vierem a ser ou não, acolhidas nas decisões finais.

Por fim, qualquer que seja a dimensão, na qual os pesquisadores estão engajados, ela somente se materializa na produção de documentos escritos. Quando pesquisadores elaboram pesquisas, eles produzem artigos; quando participam de processo de inovação, depositam patentes ou divulgam notas técnicas ou manuais de utilização; quando se envolvem com a 
docência, dirigem teses, elaboram manuais, apostilas; quando participam de programas públicos, redigem projetos para obter subvenções e relatórios justificando a utilização dos recursos e, como mencionado anteriormente, se se consagram à popularização, elaboram livros, roteiros, contribuem para a redação de regulamentos, de pareceres etc. Considerado nas cinco dimensões expostas, a pesquisa é uma vasta empresa de escritura: ela prolifera documentos de todos os tipos, aparece na página 12.

\section{O N C L U SÃ O}

"Somente se conhece bem um fenômeno quando é possível expressá-lo em número"

Lord Kelvin

Diferentemente da definição de bibliometria proposta por Pritchard, muito geral, que não indicava uma finalidade, a cientometria, embora se caracterize fundamentalmente, como um reducionismo bibliométrico, surge, no entanto no contexto de uma proposta de seu idealizador, Solla Price, de constituir-se como um arcabouço teórico da disciplina "Ciência da Ciência".

A razão para este fato tem relação direta com os desafios sócio-econômicos da era moderna, caracterizada essencialmente, pela reconhecida e certificada importância que a ciência assume junto à sociedade.

Atividade complexa e de alto risco, envolvendo investimentos financeiros vultuosos e de longo prazo, com resultados de natureza sempre intangíveis e, em geral, através de representações pouco acessíveis aos não iniciados, a gestão da atividade de pesquisa exige não só o desenvolvimento e a formulação de métodos e técnicas para quantificar os seus resultados, mas também, e principalmente a formação de grupos de pesquisa para compreender os fenômenos da criação do conhecimento e transformá-los, através de processos de codificação, em resultados econômicos, segundo as 5 (cinco) dimensões de impacto da pesquisa aqui relatadas.

A aptidão de codificar os conhecimentos permite a externalização da produção do conhecimento e autoriza o sistema produtivo a adquirir quantidades mais importantes de conhecimento a um dado custo.

Mas, essa externalização, que reduz os custos de operação, está ligada à não excludência, uma das características econômicas do conhecimento - bem fluido e portátil -, que torna difícil recompensar àquele que arcou com os elevados custos fixos da própria codificação.

Estruturada, na concepção de Solla Price, a "Ciência da Ciência", embora já seja hoje considerada uma disciplina em idade adulta, com um crescimento espetacular, em razão de haver mantido sua unidade, seu foco central, sem se dispersar em tendências, apesar da diversidade de suas orientações e aplicações, constata-se pelo que ficou exposto neste trabalho, que não há, por parte dos profissionais atuando na área, concordância com respeito aos conceitos e terminologias utilizados.

Acresce-se a isto o fato de que, os repertórios dos acervos científicos consagrados, como no caso do ISI, não haverem sido criados para medir a performance dos pesquisadores, das equipes ou dos laboratórios. Esses repertórios permitem essencialmente que se estabeleçam as relações que existem entre os diversos trabalhos de pesquisa, realizados em nível mundial. Há assim um desvirtuamento e, conseqüentemente, é extremamente perigoso utilizar dados que foram, inicialmente concebidos para estudos de análise global e qualitativas, utilizá-los para fins de tomada de decisão pelos gestores públicos.

Consciente do nível de complexidade e, de que há ainda muito a ser feito principalmente em nível de infra-estrutura para produzir os 
resultados esperados, todas as agências nacionais de expressão, que se preocupam e promovem estudos de avaliação da produção científica para fins de elaboração de política pública de pesquisa, vêm estimulando a constituição de fontes de dados, a formação de pesquisadores na área, o desenvolvimento e formulação de indicadores e métodos específicos e apropriados aos seus interesses.

É neste contexto, que se incluem o SciELO, a plataforma Lattes, iniciativas das

\section{REFERÊ N CIAS}

BROADUS, R.N. Toward a definition of bibliometrics. Scientometrics, v.12, n.5-6, p.373-379, 1987.

BROOKES, B.C. Comments on the scope of bibliometrics. Journal of Information Science, 12, p.45-51,1986.

CHAUMIER, J. Systèmes d'information: marchés et technologies. Paris: Entreprise Moderne d'Edition, 1986. $117 p$.

CALLON, M.; COURTIAL, J-P.; PENAN, H. In: LA SCIENTOMETRIE. Paris: Presses Universitaires de France, 1993. 126p. (Collection Que sais-je?, v. 2727).

DOBOROV, G.M.; KORENNOI, A.A. The information basis of scientometrics. In: ON THEORETICAL: problems of informatics. Moscou: Viniti for FID, 1969. p.165-191.

DUTHEUIL, C. L'état de l'art de la bibliométrie et de la scientométrie en France et à l'étranger. Rapport pour le compte du SGDN no. 24/SGDN/STS/VST/5, 1991. 64p.

HULME, E.W. Statistical bibliography in relation to the growth of modern civilization. London: Grafton, 1923. $44 p$.

MEADOWS, A.J. Theory in information science. Journal of Information Science, v.16, n.1, p.59-63, 1990.

PRICE, D.S. Little science, big science. New York: Columbia University Press, 1963. 118p.

PRICE, D.S. The structures of publication in science and technology. In: GRUBER, D.H.; MARQUIS, D.G. agências de incentivo e financiamento da pesquisa de nosso país. De forma modesta, inclui-se também a iniciativa de nosso projeto de pesquisa, ainda numa fase embrionária, que se propõe nuclear discussões, liderar grupo de pesquisa na área e formar recursos humanos aptos ao desenvolvimento de indicadores, de projetos de fontes de informação, de análise e interpretação de resultados, subsidiar agências de financiamento público de pesquisa e seus gestores.

(Eds.). Factors in the transfer of technology. Cambridge, Mass: The MIT Press, 1969. p.91-104.

PRITCHARD, A. Statistical bibliography or bibliometrics? Journal of Documentation, v.25, n.4, p.348-349, 1969.

QUONIAM, L. Bibliométrie sur des références bibliographiques: méthodologie. In: DESVALS, H.; DOU, H. (Org.). La veille technologique: l'information scientifique, technique et industrielle. Paris: Dunod, 1992. p.243-262.

RAVICHANDRA RAO, I.K. Métodos quantitativos em biblioteconomia e ciência da informação. Brasília: Associação dos Bibliotecários do Distrito Federal, 1986. 269p.

ROSTAING, H. La bibliométrie et ses techniques. Tolouse: Sciences de la Société, 1996. 131p.

ROUSEAU-HANS, F.; THIL, J. Veille et informatique: des besoins aux solutions. Technologies Internationales, Strasbourg, n.39, p.33-36, 1997.

SANTOS, R.N.M. et al. Balanço de pagamentos tecnológico : indicadores e análise. In: LANDI, F.R.; FURTADO, J. (Org.). Indicadores de ciência, tecnologia e inovação 2001. São Paulo: FAPESP, 2002. p.7:1-7:47.

VAN RAAN, A.F.J. (Ed.). Handbook of quantitative studies of science and technology. Amsterdam: Elsever, 1988. p.1-8.

XAVIER, P. Aux sources de la scientométrie. Dossier Solaris, n.2, Bibliométrie, Scientométrie, Infométrie. Available from: <http://www.info.unicaen.fr/bnum/ jelec/Solaris/d02/2polanco1.html>. Acess: 16 jan. 2003. 